\title{
Enhancing the Inclusive Self-Efficacy of Preservice Teachers through Embedded Course Design
}

\author{
Lucia Zundans-Fraser and Julie Lancaster \\ School of Teacher Education, Charles Sturt University, Panorama Avenue, Bathurst, NSW 2795, Australia \\ Correspondence should be addressed to Julie Lancaster, jlancaster@csu.edu.au
}

Received 1 August 2012; Revised 21 September 2012; Accepted 22 October 2012

Academic Editor: Michael Bender

Copyright ( $) 2012$ L. Zundans-Fraser and J. Lancaster. This is an open access article distributed under the Creative Commons Attribution License, which permits unrestricted use, distribution, and reproduction in any medium, provided the original work is properly cited.

\begin{abstract}
This study was an initial investigation into the effects of Embedded Design on the self-efficacy of pre-service teachers studying inclusive education. Forty-one participants completed pre- and postquestionnaires to determine differences in self-efficacy prior to and again at completion of an inclusive education course in an undergraduate teaching degree. A modified version of the scale developed by Hickson (1995), the "Self-Efficacy toward Future Interactions with People with Disabilities" (SEIPD) was employed for data collection. This data was supplemented by way of anonymous formal student feedback collected from the university. Findings indicate that the theoretically designed course did in fact significantly improve self-efficacy between pre- and postoccasions. Limitations of the present study are discussed as well as implications for future practice in the design of preservice courses for inclusive education.
\end{abstract}

\section{Introduction}

One of the major changes in the preparation of teachers for mainstream schools has been the need to prepare them for the diverse student populations they will be increasingly required to teach [1]. A number of studies have demonstrated that participation in a preservice course in special or inclusive education positively influences the attitudes and self-efficacy of preservice teachers $[2,3]$.

Despite positive effects, mandatory inclusive education courses have been subject to criticism for an overemphasis on knowledge acquisition instead of equipping preservice teachers with the practical skills required for teaching in an inclusive classroom [4-6]. This criticism reflects broader international concern about whether the preparation teachers receive for inclusion is adequate [1, 7-9]. A mismatch between preservice teacher education and the reality of working conditions for teachers has been identified as a major reason for high levels of attrition in inclusive education [10]. The limited exposure to inclusive education experienced by preservice teachers, and the gap between preparation and practice for inclusion, has created a context for the examination of course design [2].
Levels of self-efficacy that preservice teachers hold towards inclusive practice is an important key to addressing this situation. Bandura [11], a key proponent of self-efficacy, defines the concept as the beliefs an individual has about their ability to perform tasks which influence how they feel, think, and act. In the teaching context, self-efficacy is facilitated by mastery experiences, physiological and emotional cues, vicarious experiences, and verbal persuasion [12].

Studies to date have examined self-efficacy in the school context with teachers and students, although little has been focused specifically on the field of inclusive education [13, 14]. Numerous studies have looked at preservice teachers and their attitudes, sentiments and concerns about teaching children with disabilities [15-17]; but few have focused specifically on self-efficacy and its potential to direct preservice teacher beliefs in their own capabilities when working with these students $[18,19]$. There are also unique issues relating to the theory transfer into practice in teacher education with often limited detail regarding what goes on in a session in order to try and prepare students for conditions that will be found in the field $[2,20,21]$. The following studies attempt to respond to these limitations and provide an impetus for the current study. 
One study to provide details about course design was a study by Lancaster and Bain [22] who compared the growth in self-efficacy of preservice teachers under three different course design conditions. The results of this study influenced subsequent program design and moved course design away from the traditional categorical model used in inclusive education to a pedagogical approach. The benefits of such pedagogical approaches (including explicit teaching, cooperative learning, and task analysis) in inclusive education and the impact of self-efficacy were subsequently examined in further research done by these authors [2] in the elementary context.

The importance of various sources of self-efficacy within a science curriculum course for preservice teachers was examined by Palmer [20] in 2006. Palmer used the sources identified by Bandura: mastery experiences, vicarious experiences, visual persuasion, and physiological states as a starting point and then determined additional sources of content mastery, pedagogical mastery, and situated mastery as relevant to his findings. One hundred and ninety-thirdyear students in a preservice teacher education program took part in the research. Two formal surveys were administered with pre- and postquestionnaires specific to science. The informal surveys asked preservice teachers to describe what best assisted their learning about a particular topic of the week. Palmer found that the main source to enhance selfefficacy was cognitive pedagogical mastery. The relevance of the current study was the use of Bandura's sources as well as the additional three sources that Palmer proposed. Our intention was to apply this work to the field of inclusive education and utilise formal surveys in this field as pre- and postsources of data.

Field experiences of preservice teachers were examined by Lastrapes and Negishi [24] to determine if they had an impact on cultural consciousness and self-efficacy for teaching diverse learners. Forty-six participants were enrolled in an introduction to diversity course and given preand postquestionnaires. Content analysis of the reflections was used to determine the cultural awareness indicated by Bandura's sources of self-efficacy. Bandura's sources of self-efficacy were mentioned and linked to the analysis of the written reflections given by preservice teachers with the authors focusing on four sources of self-efficacy: performance accomplishment, vicarious experiences, verbal persuasion, and emotional arousal. Our intention was to similarly make links to Bandura's sources although these links would be made through quantitative data results rather than through qualitative reflections. Lastrapes and Negishi's [24] work ultimately found that self-efficacy was not directly enhanced by field experiences but we hypothesise that selfefficacy may be enhanced by a theoretically designed course. With this in mind, we did not incorporate a field experience but rather paid extensive attention to describing the theory behind the course and the course structure.

Risks to self-efficacy among special education intern teachers were investigated by Lee et al. [25]. The authors surveyed 154 preservice teachers using an adaptation of Gibson and Dembo's [26] scale. They included items of personal teaching efficacy (PTE) which were identified as the levels of teacher confidence in their ability to promote students' learning, general teaching efficacy (GTE), the levels of teacher confidence about the power of teaching, and added special education knowledge and competency skills based on Council of Exceptional Children (CEC) standards. The results demonstrated that the intern teachers had higher levels of PTE than GTE and that they rated highly on their knowledge and skills of CEC competencies. Although PTE and GTE were independent of each other, there were strong correlates of confidence in knowledge and skills relating to sense of control over major issues they faced in the classroom. The scale developed by Lee et al. [25] was designed specifically to address students with special needs and teachers that had already completed an undergraduate degree and were engaged in additional training in the field of special education. It is of interest to this study due to the focus on special education and the items that were incorporated in the scale to measure the construct of self-efficacy.

Forlin et al. [1] engaged in a study examining 603 preservice teachers' attitudes, sentiments, and concerns about inclusive education in teacher preparation programs in four countries: Australia, Canada, Hong Kong, and Singapore. All cohorts were comprised of preservice teachers intending to teach in mainstream classrooms in preschool, elementary, or secondary settings. The Canadian setting was unique in that inclusive education content was infused throughout the program rather than a "stand-alone" course looking at catering for the needs of children with diverse abilities. The data from the four countries was treated as one data set for the purposes of this particular paper which focused on the role demographic differences play in changing attitudes, sentiments, and concerns about inclusive education. The researchers found that previous involvement and contact with students with disabilities resulted in more positive attitudes and minimised levels of concern.

Forlin et al. [1] concluded that a primary aim of preservice teacher education courses in relation to inclusion needs to focus on improving the self-efficacy of preservice teachers in order to help them develop more positive attitudes, reduce their concern's and increase their understanding and confidence.

As noted in the studies above, the use of researchbased practices for inclusive education is well established. What is missing is a theory base that holds these strategies together and allows for ongoing feedback and improvement in practice. Theoretically driven course design would allow a course to be developed based on the tenets of a theory; in this instance, the approach was based upon theoretical work related to self-organisation and complex adaptive systems [27-29]. Theories of self-organisation have particular application to the challenges of higher education course development as they explain how agents in systems work at all levels together to produce solutions. Those individual agents or participants generate collaborative solutions by working together and in doing so, they transcend their individual capacities. We decided to take one of the six theoretical principles of self-organisation, that of Embedded Design, and look at how this particular principle impacted the self-efficacy of students in an inclusive education course. 
Embedded Design creates self-repeating patterns by expressing simple rules in design by embedding these design features in all others [30]. In the case of Bain's research, Embedded Design involved explicitly repeating the content of cooperative learning (or any other inclusive pedagogy selected) in all parts of the topic design. In practice, this meant that the roles and structures discussed in the lecture were created and modeled in the tutorial. Students were then required to practice the specific pedagogy, listen to feedback on their own practice, and provide feedback to others on theirs. This feedback was reflected upon and incorporated in their lesson design assessment submissions.

Embedding particular design principles throughout the course ensured cohesion in both content and delivery. Contemporary needs in education were also embedded through this process to ensure elements such as instructional differentiation were reiterated throughout the course design process. The design integrated common aspects such as peer feedback, authentic assessment, advance organisers, and concept mapping into the design framework.

The premise in this study was that the use of Embedded Design would assist in the maintenance of knowledge and skills required for successful inclusive practice. Embedded Design was utilised in this setting to incorporate well established research-based pedagogies of inclusion: explicit teaching, cooperative learning, and the use collaborative practice for problem solving. Instruction focussed on application of three pedagogies of inclusion in a course designed using the principle of Embedded Design and the effect this had on student-levels of self-efficacy.

The intention of the present study was to extend the work done in earlier research and look at self-efficacy amongst preservice teachers enrolled in an early childhood and elementary program. We hypothesised that levels of selfefficacy would increase from pre- to postoccasions following the application of the Embedded Design principle. follows.

The research question addressed in the study was as

(i) Does self-efficacy increase as a result of participation in a course utilising Embedded Design characteristics?

\section{Method}

2.1. Participants. A total of 41 preservice teachers participated in this study, all of whom were second year students enrolled in the early childhood and elementary education program in an Australian regional university. Of the total, 3 were males and 38 were females. The 3 males were removed from the analysis as this small number renders the male sample untestable. Thirty-two of the participants had no previous experience of individuals with a disability. One student had a disability themselves, two had direct experience through a family member, three had engaged in part-time and casual work where they had encountered individuals with disabilities and three others had incidental contact through various community activities.
2.1.1. Setting. The teaching sessions of the 14 -week course were held in a lecture theatre for the lectures and a smaller teaching space for the workshops. Each workshop included approximately 20 preservice teachers.

2.1.2. Independent Variable. The Embedded Design of the inclusive education course served as the independent variable in this study. The following areas will be elaborated: subject content, assessment (quizzes and presentations), and lesson design in order to provide sufficient details about the course.

2.1.3. Course Content and Assessment. The topics covered during the course included legislation and policy, inclusive practice, family-centred practice, individualizing curriculum, early intervention, social interactions, communication, and transition. A key focus throughout the course was the application of three pedagogies of inclusion-collaborative practice, explicit teaching, and cooperative learning, to apply the concept of Embedded Design in an authentic manner. Lectures were utilised to present more of the theory base of these pedagogies and their relevance to inclusive education whereas in workshops, preservice teachers were required to build lesson designs using the inclusive pedagogies. All preservice teachers were required to complete prereading on the weekly topics in preparation for lectures and the workshop quizzes.

Three assessment types were embedded in the course structure-a weekly quiz, a presentation, and explicit lesson design. The quizzes provided a theoretical and practical basis for understanding and implementing inclusive classroom and centre practices. Each of the multiple choice quizzes related to content in the weekly readings and had been covered in the related lecture. The purpose of the presentations was to engage preservice teachers in gaining a deeper knowledge around topics of interest in inclusive education. They were encouraged to work on these collaboratively in line with the philosophy of the course, although they were permitted to complete individual presentations. The presentation was required to meet five key criteria: a definition of the chosen disability, causes and/or possible causes, key features of the disability, methods used for identification, and implications for inclusion.

The final assessment involved lesson design. Preservice teachers were taught how to build lesson designs using each of the pedagogies and then asked to differentiate these designs for an inclusive classroom or centre. In each case, the teaching approach that constituted the focus of the workshop was employed to teach the workshop. For example, preservice teachers learnt about collaborative practice by examining and discussing what factors made up a collaborative lesson and then using collaborative practice as their medium for learning and instruction throughout the workshop $[9,31]$. The same approach was applied to the design and implementation of workshops on task analysis, explicit teaching and cooperative learning.

The Embedded Design principle was used in all aspects of the course [30]. This meant that organisational and assessment structures were determined at the beginning of 
the course and were applied consistently throughout the session. This embedding was accomplished in the course design and implementation by using inclusive pedagogies such as collaborative practice and explicit teaching in all workshops to learn about these approaches. For example, in the first workshop, preservice teachers were placed in collaborative groups, were taught a collaborative problemsolving process based on work by Friend and Cook [31], and practiced with basic problems created by the instructor. The application of this process became more sophisticated and concrete through their work on lesson designs.

Preservice teachers worked collaboratively on their lesson designs and were expected to be prepared for each workshop. Unlike earlier work by Lancaster and Bain [2, 22], preservice teachers were not required to have a full lesson prepared prior to workshops or provide suggestions for improvement through a formal feedback process. This aspect of the workshops was a lot more fluid; but as the group was highly cohesive and a supportive and comfortable environment had developed, the provision of feedback naturally emerged.

2.2. Dependent Variable. The Self-Efficacy toward Future Interactions with People with Disabilities Scale (SEIPD) [23] was employed in this study. The scale is comprised of 15 items in three areas: willingness to initiate behaviour; willingness to expend effort in completing behaviour; persistence in the face of adversity [23]. The SEIPD employs a Likert 8-point scale, ranging from definitely false to definitely true with no midpoint as a format for responding; for example "I am able to plan and organise appropriate activities for my students" [25, page 111]. Scale items are included in Table 1.

The reversed items included items: 4, 6, 8, 11, and 12 and were reversely scored. At the time of development, Hickson reported reliability of the SEIPD using test-retest and alpha coefficients, employing a sample of 180 teachers and nurses. A mean alpha coefficient of 0.87 was reported for the SEIPD, whereas test-retest reliability produced a reliability coefficient of 0.8 over a 4 -week interval and 0.68 over a 6 week interval [23]. Factorial validity was established using principal component analysis. Both orthogonal and oblique rotations gave identical results with only one factor extracted, indicating that items within the scale were measuring the same construct and accounting for an average of $55.1 \%$ of the variance [23].

In the current study, factor analysis was utilised to determine if more factors were present in the SEIPD scores. Using exploratory factor analysis, the following results were found. Kaiser-Meyer-Olkin measure of sampling adequacy provided the score of 0.823 which ranked very high to indicates there were sufficient responses in the data set to run the analysis.

The dimensionality of the 15 items from the Self-Efficacy measure was analysed using maximum likelihood factor analysis. Three criteria were used to determine the number of factors to rotate: the a priori hypothesis that the measure was unidimensional, the scree test, and the interpretability of the factor solution. The scree plot indicated that that the initial
Table 1: Self-Efficacy toward Future Interactions with People with Disabilities [23].

(Q1) I feel confident in my ability to be able to teach students with disabilities.

(Q2) I am able to provide individuals/students with appropriate programs.

(Q3) I can adapt my practices to suit individual needs.

(Q4) I do not feel in control of any unforeseen situation that may arise during any interaction.

(Q5) I am confident that I will quickly lose any fear or apprehension.

(Q6) I do not feel competent in relation to my skills in this area.

(Q7) When individuals make progress, it is due to the input I have made.

(Q8) When confronted with a challenging situation I would be likely to give up.

(Q9) I am able to plan and organise appropriate activities for students with disabilities in my class.

(Q10) I am able to attain any goals I set for myself in this area of work.

(Q11) I have a low expectation of my performance in this area.

(Q12) I do not look forward to the next time I teach students with disabilities.

(Q13) It is rare that I feel failure and frustration when working in this area.

(Q14) These students will benefit greatly from my interactions with them.

(Q15) I see my future interactions with students with a disability as successful.

hypothesis of unidimensionality was incorrect. Based on the plot, two factors were rotated using the Oblimin with Kaiser normalization procedure. The rotated solution yielded two interpretable factors: personal teaching efficacy (PTE) and skill level. The PTE factor accounted for $48.12 \%$ of the item variance and the skill level factor accounted for $10.78 \%$ of the item variance. Only one item loaded on both factors (item Q6) and could probably be eliminated in future use of the questionnaire. Cronbach's Alpha was calculated to be $\alpha=$ 0.89 for items selected above called "PTE." Tukey's estimate of 1.24 is satisfactory to generate a normal distribution of results. The factor "skills" resulted in $\alpha=0.86$ and Tukey's estimate of 1.13. The items that fell within the PTE factor included items: $3,5,6,7,8,10,11,12,13$, and 14 . Those that fell within the skills factor included 1, 2, 4, 9, and 13 .

Further data were also sourced from anonymous student feedback collected by the university prior to the end of session. This feedback was made available to lecturers following grade release and consists of 11 core items with Likert scale of 7 ranging from "very strongly agree" to "very strongly disagree." This is a standardised university teaching evaluation survey that is voluntarily and anonymously completed by students in all courses across the university. Examples of the items include: Clear guidelines were provided for all assessment tasks; I was given guidance on how to improve my work; Teaching was clearly directed 
TABLe 2: Means overall at pre- and post-occasions.

\begin{tabular}{lcc}
\hline & Total pre-SEIPD & Total post-SEIPD \\
\hline Mean & 84.95 & 97.82 \\
Std. deviation & 18.01 & 10.19 \\
\hline
\end{tabular}

TABLe 3: Mean scores for SEIPD questions at pre- and postoccasions.

\begin{tabular}{lcccc}
\hline \multirow{2}{*}{ SEIPD scores } & \multicolumn{2}{c}{ Before } & \multicolumn{2}{c}{ After } \\
& Mean & SD & Mean & SD \\
\hline Q1 & 5.05 & 1.987 & 6.54 & 1.027 \\
Q2 & 5.02 & 1.753 & 6.44 & 0.896 \\
Q3 & 5.78 & 1.605 & 6.83 & 1.181 \\
Q4 & 5.02 & 1.753 & 5.95 & 1.499 \\
Q5 & 5.80 & 1.600 & 6.51 & 0.898 \\
Q6 & 4.90 & 1.934 & 6.24 & 1.670 \\
Q7 & 5.27 & 1.342 & 5.9 & 0.831 \\
Q8 & 6.80 & 1.418 & 7.17 & 0.919 \\
Q9 & 4.88 & 1.763 & 6.78 & 0.852 \\
Q10 & 6.10 & 1.158 & 6.66 & 0.855 \\
Q11 & 5.61 & 2.011 & 6.68 & 1.128 \\
Q12 & 6.46 & 1.704 & 6.98 & 1.475 \\
Q13 & 5.23 & 1.847 & 5.53 & 1.633 \\
Q14 & 6.12 & 1.364 & 6.63 & 1.090 \\
Q15 & 6.53 & 1.467 & 7.20 & 0.872 \\
\hline Total & 84.95 & & 97.82 & \\
\hline
\end{tabular}

towards the objectives of the subject. Additional positive or negative written comments could be made if the students chose to complete this section of the form.

\section{Results}

The paired sample $t$-test conducted to evaluate the impact of Embedded Course Design on Student's scores on the SEIPD at pre- and postoccasion revealed a statistically significant increase in SEIPD scores from time $1(M=84.95, \mathrm{SD}$ $=18.01)$ to time $2(M=97.82, \mathrm{SD}=10.19), t(37)=-6.22$, $P<.001$ (two tailed). The effect size (Cohen's $d$ ) was 1.06 indicating a large effect size.

Table 2 presents the overall means and standard deviations for the SEIPD scores.

Further details are presented for individual questions in Table 3.

Table 3 summarizes the results for each question on the pre- and postoccasion.

Questions that scored the lowest at pretest included Q6 and Q9: "I do not feel competent in relation to my skills in this area; I am able to plan and organise appropriate activities for students with disabilities in my class."

Many of the preservice teachers had no prior experience with anyone who had a disability. It certainly indicates that the preparation they had completed to date in their university program had not prepared them for this area of teaching, which is supported by research mentioned earlier $[1,7-9]$. By the posttest occasion, the mean scores for these items had shifted from less than 5 to scores of 6.24 and 6.78 , respectively, indicating that the preservice teachers felt the course had enabled the skills they will need when working with diverse student populations.

The range of scores at posttest occasion was 5.90-7.20. The highest scoring items were items 8 and 15, "When confronted with a challenging situation I would be likely to give up." The negative slant of this item meant it was scored backwards so that a high score of 8 was gained from a "definitely false" response. Item 15 was "I see my future interactions with students who have a disability as successful." Both these items indicate a high personal teaching efficacy (PTE) for inclusive education from the scale.

Results from the anonymous university feedback data were analysed by university personnel by taking means of the core likert items and comparing similar course content areas across faculty teaching courses. Response rates from the feedback are very low and could not be analysed statistically. Data presented are given as an illustration.

Student feedback for the likert responses on the 11 core items concur with discussions of self-efficacy sources noted by Bandura [11] and Palmer [20]. In every instance of the 11 core feedback items included, the single course score rated higher than the entire teaching school mean with means scores ranging from 5.16-6.42 out of a possible 7. Further 6 items were customised and added to the 11 core including: "the... use of examples helped my understanding" and "the academic made clear and practical application of the subject." These additional items scored an average of 6.78 out of a possible 7 .

Written student feedback provided as part of the anonymous course university feedback process indicate that the various student comments support Palmer's (2006) suggestion that cognitive pedagogical mastery was the most reported source of self-efficacy when looking at student's reflections on learning. Student comments that particularly focused on assessment and content were purposefully selected to illustrate this source in action: "The assessments were helpful in understanding about inclusive education and that it isn't hard to adapt the curriculum, classroom, etc., as it would seem" (Student $\mathrm{x}$ ); "The extra class on explicit learning design was very helpful" (Student y) and "Excellent teaching strategies used" (Student $\mathrm{z}$ ). Results suggest that these are two key aspects that are at the forefront of a student's engagement when completing a course-the assessments that they need to complete and the content of the course itself.

The students also touched on aspects of content mastery that was indicated by Palmer in 2006, and in a particular case mapped to the word itself: "The weekly quizzes were good in keeping me keep up with the readings and my understanding of the subject" (Student a) and "As this subject covers a lot of content we could have quite easily become restless each week but we weren't!" (Student b). The interwoven nature of the content and pedagogical mastery comments is not unusual as these two fields were inextricably linked as the delivery of course-specific content was reliant on pedagogy as a focus. 


\section{Discussion}

We hypothesised that self-efficacy would increase through the application of the Embedded Design principle to a course that enabled preservice teachers to build mastery in inclusive pedagogies. A paired sample $t$-test indicated that there was a significant difference between pre- and postoccasion. The effect size of 1.06 is considered substantial.

Previous studies have found that self-efficacy increased following the completion of a course of study in inclusive education at undergraduate level $[24,25]$. What has been lacking in many of the aforementioned studies is a clear description of what constituted the course structure and design in order to have such an impact on self-efficacy. Using Embedded Design principles employed in this course to match more closely the tenets proposed by Bandura as mediating factors for self-efficacy allowed for a closer insight into what worked and what did not. Caution must be exercised though as we were only able to report on pre and postdifferences based on a self-report of self-efficacy. It was not possible to make more substantial claims about where the actual differences came from. Disentangling the different facets in a more empirical way would be of interest and would certainly be an avenue for future exploration. Notwithstanding this caution when interpreting these findings, the following is a discussion of results incorporating possible avenues for future empirical exploration.

The design elements of this course have been carefully described and might be linked to Bandura's sources of selfefficacy. Enactive mastery experiences, vicarious experiences, social persuasion, and physiological indexes were incorporated into the course design in the following ways.

Enactive mastery was expected by way of the differing assessment items required with knowledge being expanded across the use of quizzes, presentations then finally culminating in lesson designs that incorporated the pedagogy of choice as well as iterations of differentiation that may be required in classroom. The mastery of the content was repeatedly embedded in the design. Vicarious experiences occurred through preservice teacher presentations and also the collaborative groups where preservice teachers were enabled to estimate their capabilities in comparison to others as they worked in their collaborative groups. Social persuasion was experienced through feedback given by peers as well as the instructor during workshop activities; physiological indexes were often commented upon prior to quizzes, during presentations in front of their peers and in the collaborative process of lesson design preparation. All of these sources were incorporated into the design of the course through the principles of Embedded Design which were woven throughout all aspects of the course.

The nature and characteristics of the Embedded Design course also captured the additional sources of self-efficacy identified by Palmer [20] in his science classes. We cannot empirically concur with Palmer that Bandura's sources can be extended to include content mastery, pedagogical mastery, and situational mastery; in this study those sources were not measured. However, based on the description given, the Embedded Design ensured that content mastery was enhanced by the weekly quizzes and the presentations. The content was presented in a way that mastery was ensured before moving on to the next assessment item. Pedagogical mastery was the key focus of content covered in the course and was scaffolded formatively via differentiated lesson designs. Preservice teachers also witnessed expert models during class with the instructor modelling pedagogies and followed by peers modelling them as well. Palmer [20] found cognitive pedagogical mastery to be the most reported sources of efficacy when analysing his student's reflections on their learning. This is the closest related source found in the structure of this current study. The preservice teachers were given instruction on how to develop lesson content using the research-based characteristics of various pedagogies. Cognitive content mastery (i.e., understanding the concepts behind differentiation of various topics taught) was also embedded in the requirement for differentiation using the various pedagogies.

Lastrapes and Negishi [24] were able to extrapolate percentages of perceived importance preservice teachers attached to the different sources of self-efficacy: 70\% from their own mastery experiences, $20 \%$, vicarious experiences and the remaining $10 \%$ from verbal persuasion. All of these elements were incorporated in the course through the use of Embedded Design principles even though it was a classbased course rather than a field experience. Large cohorts of preservice teachers do not always allow for field experiences to be tied to every course they complete. As Lastrapes and Negishi [24] and Lancaster and Bain [2] found, self-efficacy is not necessarily maximally enhanced by field experiences. A theoretically designed course has statistically more impact [2]. The common themes identified by Lastrapes and Negishi [24] might be investigated more empirically in future studies.

Ruys et al. [19] present findings about the impact of selfefficacy on conceptions towards using collaborative learning in classrooms. They found that even though it was a highly valued strategy, preservice teachers did not prefer to collaborate themselves during their own learning process. Results indicated that collaborative learning was only implemented once in a while in teacher education classes and preservice teachers did not feel that they were adequately trained in the use of collaborative learning pedagogies for their future practice. Although it is recognised that ideally instructional strategies would be embedded across a program, this research takes the first step of embedding inclusive pedagogies across a course. We embedded the collaborative learning throughout the course as a skill to be used in workshops and also mastered in terms of knowledge. We incorporated not only the research-based characteristics of collaborative learning, but also the means to differentiate the pedagogy.

This study made some interesting findings in terms of analysing the actual construct of self-efficacy when applied to preservice teachers studying inclusive education content. The original Self-Efficacy Scale developed by Hickson in 1995 [23] was administered to nurses and perhaps this is why only one factor was determined at that point in time. The nurses did not have the same vested interest in working with and teaching those who have a disability as did the group of preservice students studying to be teachers. The two factors 
detected here can be related to the study conducted by Lee et al. [25], which may suggest the existence of other related sources that contribute to the self-efficacy construct. It makes sense that an improvement in skill level when considering inclusive pedagogies would have an impact on the efficacy preservice teachers feel about their ability to teach students with disabilities. The analysis of the separate factors was not carried out here but could form part of future empirical study into the area.

In spite of positive findings from this initial study, caution must be exercised with interpretations of the findings.

\section{Limitations}

Any findings must be taken cautiously as a result of the limitations in using a case study framework. The first and most notable is the lack of control group to compare the selfefficacy results. The data included was sought from a single cohort of preservice teachers. The case study framework does not necessarily address the issue of controls but seeks to evaluate a single case. Future studies could improve generalizability through use of quasiexperimental design that incorporates a control group that experiences the course design differently.

Other issues include the sample size and self-report that was involved with the use of the SEIPD questionnaire. Findings generated from self-report are difficult to generalise unless there are other data sources to support findings. Students were also predisposed to the same questions at pre- and posttest occasions so they were aware of what was expected of them. Having no control groups and self-reports severely limits the generalizability for the current findings.

There is no room to speculate about long-term effects of the embedded course design, and none were made. Nor are there any claims, about the actual ability to teach in inclusive settings. To make these sorts of claims a more experimental and longitudinal study is required. Data such as direct observations would be beneficial in future research as would additional sources of information such as narratives written by the students for coding analysis.

\section{Conclusions}

In conclusion, these initial findings suggest that courses using Embedded Design principles may support improvement of self-efficacy of preservice teachers. Further empirical testing is of course required. These findings are encouraging, especially given the importance of self-efficacy and its powerful influence on teacher effectiveness and also draws attention to the design issues associated with preservice teacher education courses in inclusive education. The theoretical drivers behind course design calls for a more thorough analysis in terms of the many variables that impact preservice teacher educators. As Sari et al. [14] suggest, perhaps additional inclusive education courses should be run for preservice teachers; or, as Forlin et al. [1] found with their Canadian cohort, the inclusive education content might be embedded across a whole program rather than a stand-alone course. Enactive mastery [20] could be linked into professional placements following the conclusion of an inclusive education course. Further research is required before more definitive conclusions can be made.

Given the high attrition rates experienced by teachers entering the inclusive education field of practice, more effort needs to be expended to assist preservice teachers gain the skills and confidence they need to work with the diverse populations of students they will encounter.

\section{References}

[1] C. Forlin, T. Loreman, U. Sharma, and C. Earle, "Demographic differences in changing pre-service teachers' attitudes, sentiments and concerns about inclusive education," International Journal of Inclusive Education, vol. 13, no. 2, pp. 195-209, 2009.

[2] J. Lancaster and A. Bain, "The design of pre-service inclusive education courses and their effects on self-efficacy: a comparative study," Asia-Pacific Journal of Teacher Education, vol. 38, no. 2, pp. 117-128, 2010.

[3] K. Purdue, D. Gordon-Burns, A. Gunn, B. Madden, and N. Surtees, "Supporting inclusion in early childhood settings: some possibilities and problems for teacher education," International Journal of Inclusive Education, vol. 13, no. 8, pp. 805815, 2009.

[4] A. Ashman and J. Elkins, Education for Inclusion and Diversity, Pearson Education Australia, Frenchs Forest, NSW, Australia, 3rd edition, 2009.

[5] E. E. Boe, S. Shin, and L. H. Cook, "Does teacher preparation matter for beginning teachers in either special or general education?" Journal of Special Education, vol. 41, no. 3, pp. 158-170, 2007.

[6] A. Carroll, C. Forlin, and A. Jobling, "The impact of teacher training in special education on the attitudes of Australian preservice general educators towards people with disabilities," Teacher Education Quarterly, vol. 30, no. 3, pp. 65-79, 2003.

[7] M. C. Pugach and L. P. Blanton, "A framework for conducting research on collaborative teacher education," Teaching and Teacher Education, vol. 25, no. 4, pp. 575-582, 2009.

[8] U. Sharma, C. Forlin, and T. Loreman, "Impact of training on pre-service teachers' attitudes and concerns about inclusive education and sentiments about persons with disabilities," Disability and Society, vol. 23, no. 7, pp. 773-785, 2008.

[9] P. Foreman, Inclusion in Action, Cengage Learning, 2011.

[10] J. McLeskey and B. S. Billingsley, "How does the quality and stability of the teaching force influence the research-topractice gap?: a perspective on the teacher shortage in special education," Remedial and Special Education, vol. 29, no. 5, pp. 293-305, 2008.

[11] A. Bandura, "Exercise of personal and collective self-efficacy in changing societies," in Self-Efficacy in Changing Societies, pp. 1-45, Cambridge University Press, Cambridge, UK, 1995.

[12] A. Bandura, "Self-efficacy," Harvard Mental Health Letter, vol. 13, no. 9, p. 4, 1997.

[13] J. Lancaster, "Is it really possible? Can students with learning difficulties ever achieve higher levels of self-efficacy?" Special Education Perspectives, vol. 14, no. 2, pp. 46-61, 2005.

[14] H. Sari, N. Celikoz, and Z. Secer, "An analysis of pre-school teachers' and student teachers' attitudes to inclusion and their self-efficacy," International Journal of Special Education, vol. 24, no. 3, pp. 29-44, 2009. 
[15] E. Boling, “'Yeah, but I still don't want to deal with it'. Changes in a teacher candidate's conceptions of inclusion," Teaching Education, vol. 18, no. 3, pp. 217-231, 2007.

[16] N. Elik, J. Wiener, and P. Corkum, "Pre-service teachers' openminded thinking dispositions, readiness to learn, and attitudes about learning and behavioural difficulties in students," European Journal of Teacher Education, vol. 33, no. 2, pp. 127146, 2010.

[17] K. Hergenrather and S. Rhodes, "Exploring undergraduate student attitudes toward persons with disabilities: application of the disability social relationship scale," Rehabilitation Counseling Bulletin, vol. 50, no. 2, pp. 66-75, 2007.

[18] S. Romi and Y. Leyser, "Exploring inclusion preservice training needs: a study of variables associated with attitudes and selfefficacy beliefs," European Journal of Special Needs Education, vol. 21, no. 1, pp. 85-105, 2006.

[19] I. Ruys, H. van Keer, and A. Aelterman, "Collaborative learning in pre-service teacher education: an exploratory study on related conceptions, self-efficacy and implementation," Educational Studies, vol. 36, no. 5, pp. 537-553, 2010.

[20] D. H. Palmer, "Sources of self-efficacy in a science methods course for primary teacher education students," Research in Science Education, vol. 36, no. 4, pp. 337-353, 2006.

[21] J. N. Causton-Theoharis, G. T. Theoharis, and B. J. Trezek, "Teaching pre-service teachers to design inclusive instruction: a lesson planning template," International Journal of Inclusive Education, vol. 12, no. 4, pp. 381-399, 2008.

[22] J. Lancaster and A. Bain, "The design of inclusive education courses and the self-efficacy of preservice teacher education students," International Journal of Disability, Development and Education, vol. 54, no. 2, pp. 245-256, 2007.

[23] F. Hickson, Attitude Formation and Change Towards People with Disabilities, University of Sydney, Sydney, NSW, USA, 1995.

[24] W. Lastrapes and M. Negishi, "Foundational field experiences: a window into preserve teachers cultural consciousness and self-efficacy for teaching diverse learners," SRATE Journal, vol. 21, no. 1, pp. 37-43, 2012.

[25] Y. Lee, P. P. Patterson, and L. A. Vega, "Perils to self-efficacy perceptions and teacher-preparation quality among special education intern teachers," Teacher Education Quarterly, vol. 38, no. 2, pp. 61-76, 2011.

[26] S. Gibson and M. H. Dembo, "Teacher efficacy: a construct validation," Journal of Educational Psychology, vol. 76, no. 4, pp. 569-582, 1984.

[27] S. Kauffman, At Home in the Universe: The Search for the Laws of Complexity and Self-Organization, Oxford University Press, New York, NY, USA, 1995.

[28] I. Prigogine and I. Stengers, Order Out of Chaos: Man's New Dialogue with Nature, Bantam Books, New York, NY, USA, 1984.

[29] M. Waldrop, Complexity: The Emerging Science at the Edge of Order and Chaos, Simon \& Schuster, New York, NY, USA, 1992.

[30] A. Bain, The Self-Organizing School: Next Generation Comprehensive School Reform, Rowman \& Littlefield Education, Lanham, Md, USA, 2007.

[31] M. Friend and L. Cook, Interactions: Collaboration Skills for School Professionals, Pearson Education, Boston, Mass, USA, 4th edition, 2010. 


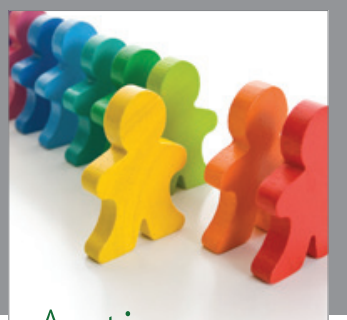

Autism

Research and Treatment
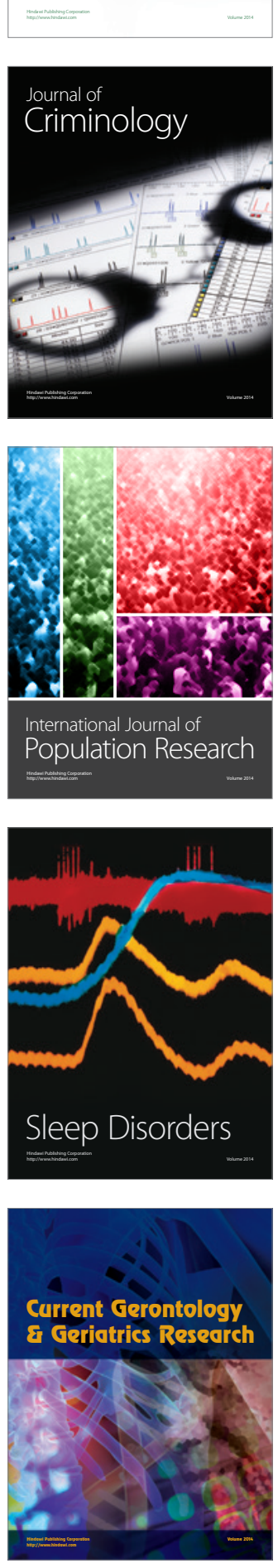
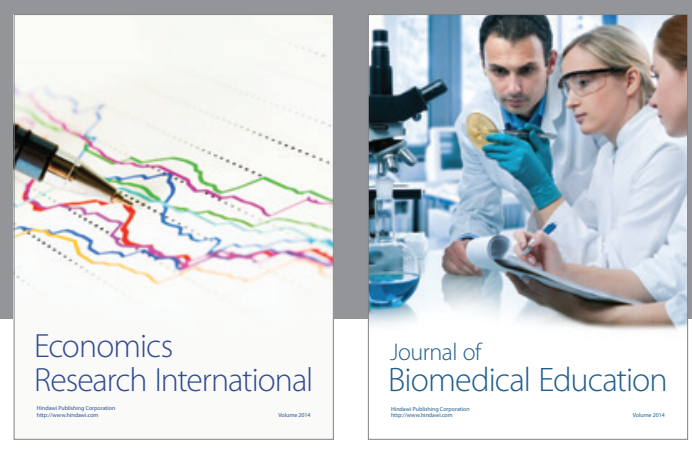

Journal of

Biomedical Education

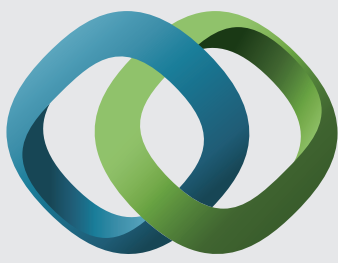

\section{Hindawi}

Submit your manuscripts at

http://www.hindawi.com
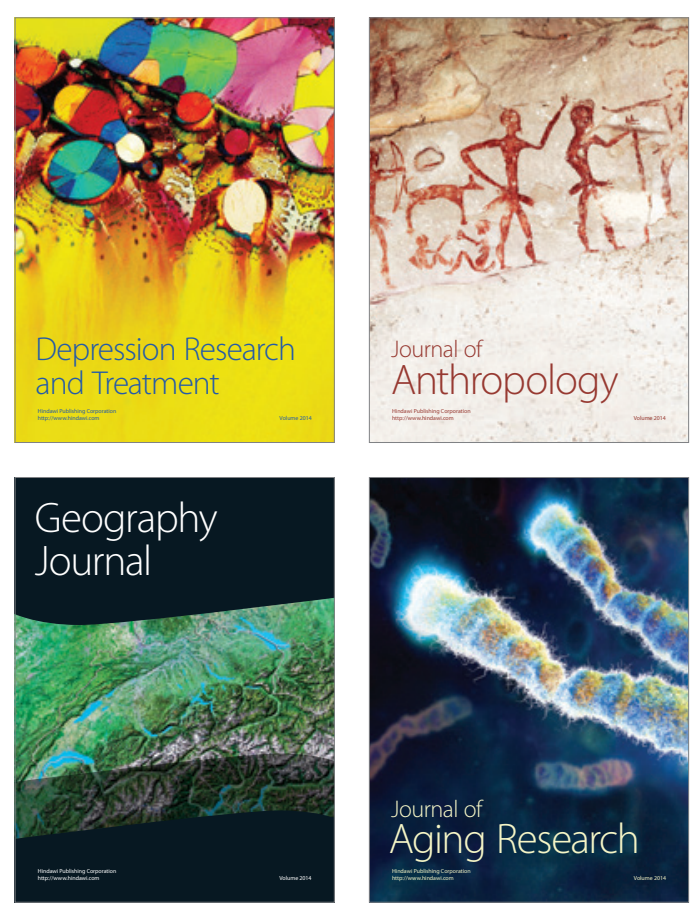

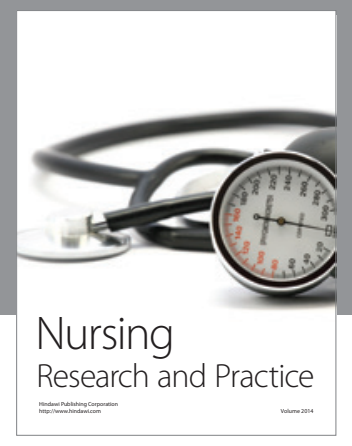

Nursing

Research and Practice

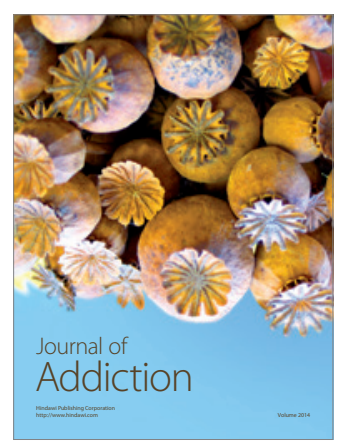

Child Development

Research

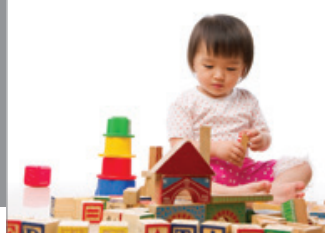

迥
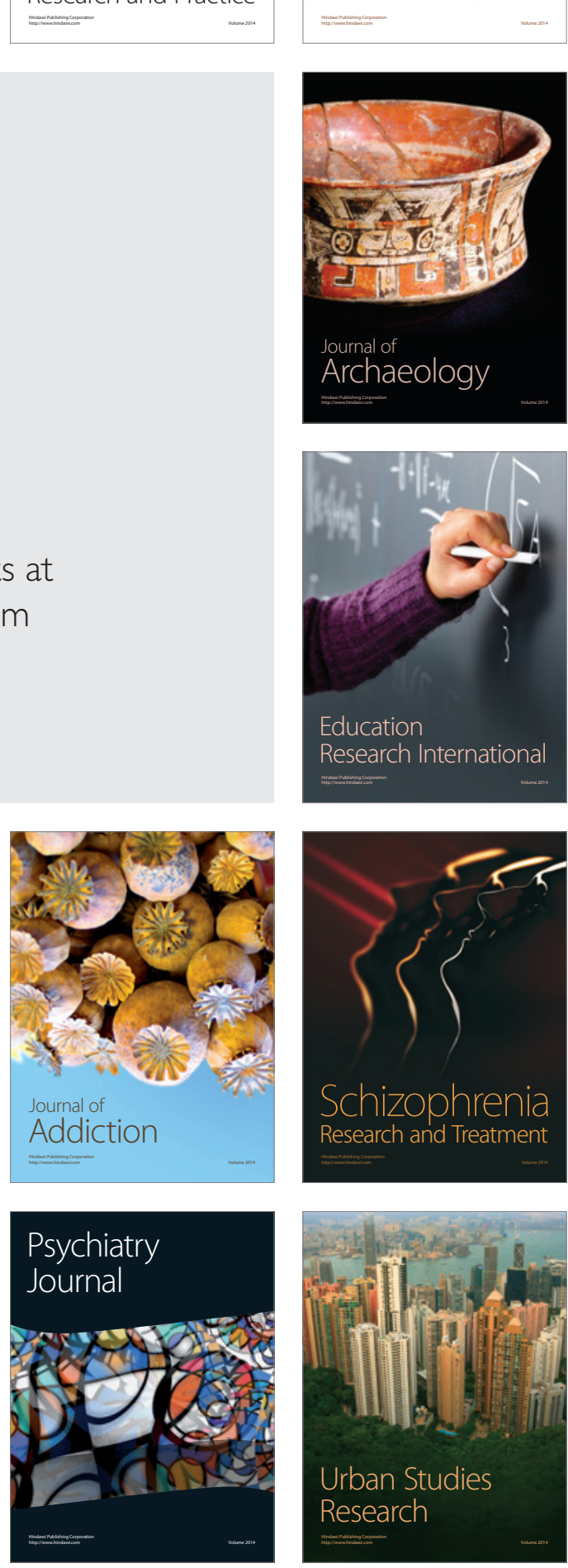